\title{
Adapting cities for a changing climate: an integrated approach for sustainable urban development
}

\author{
A. Galderisi \\ Department of Civil, Architectural and Environmental Engineering, \\ University of Naples Federico II, Italy
}

\begin{abstract}
Climate change is one of the main environmental issues challenging cities in the 21 st century. The change in climate conditions is largely due to greenhouse gas (GHG) emissions. Cities are considered as the main factor responsible for GHG emissions, whose amount could still rise due to the expected increase of urban population. Thus, climate change and the growth of urban population appear closely linked in a negative loop and the ways in which their trends will develop and interact will be of great consequence to the wellbeing of human populations in the future. Up to now, European efforts have been largely focused on the mitigation of climate change. Only recently, the EU has stressed that - even though mitigation strategies still remain a priority - a larger focus has to be devoted to adaptation measures, in order to face the unavoidable impacts and related economic, environmental and social costs of climate change.

Grounding on these premises and according to the Rio +20 Declaration "The Future we want", this contribution explores the role of adaptation planning for driving European cities towards the achievement of sustainability goals, emphasizing the need for a better integration of disaster risk reduction and climate adaptation policies in urban planning. Current Adaptation plans, in fact, are likely to become a further sectoral tool, scarcely related to policies and tools for both disaster risk mitigation and land-use planning.

Keywords: climate change, adaptation, urban planning, resilience, sustainable development.
\end{abstract}




\section{Introduction}

Due to urban lifestyle and economy, cities are responsible for more than $70 \%$ of greenhouse gas emissions [4, 5], which is the main driver of climate change. Most of the world's population currently lives in urban areas and urban population will further increase by 2050. According to the last report of the IPCC [6], the "continued emissions of greenhouse gases will cause further warming and changes in all components of the climate system. Limiting climate change will require substantial and sustained reductions of greenhouse gas emissions". Up to now, significant efforts have been addressed to promote mitigation strategies, aimed at reducing GHG emissions, while the issue of adaptation has gained importance only recently. In 2013, the EU Strategy on adaptation to climate change has been adopted. It clearly underlines that, "although climate change mitigation must remain a priority for the global community $(\ldots)$, we (...) have no choice but to take adaptation measures to deal with the unavoidable climate impacts and their economic, environmental and social costs" [2]. The focus on adaptation stems from the growing and shared awareness that, despite the efforts to reduce GHG emissions, climate change is going to occur [7] and its impacts will be particularly severe in urban areas [8], due to the concentration of people and assets. Thus, adaptation measures are receiving an increasing financial support and the pivotal role of cities in addressing climate change has been largely discussed in the last decade [9]. Nevertheless, while numerous European cities have joined the Covenant of Majors, giving rise to a mitigation strategy, few of them have started an adaptation process addressed to establish local strategies for enhancing urban resilience in face of "the unavoidable climate impacts and their economic, environmental and social costs" [2]. The recent launch, in March 2014, of the Mayors Adapt Initiative, set up by the European Commission could largely increase the number of cities involved in climate adaptation.

Hence, due to the growing awareness of the need for adaptation and of the pivotal role of cities, this paper will explore the potential role of adaptation processes for mainstreaming disaster risk reduction as well as climate adaptation policies into urban planning processes, in order to promote a sustainable urban development. Current adaptation plans are indeed scarcely related to policies and tools for both disaster risk mitigation and land-use planning. On the opposite, urban planning - which has largely contributed to the occurrence of more frequent, severe and unpredictable climate-related disasters in urban areas - could provide a framework under which competing goals and land uses could be negotiated and reconciled [10], preventing the adaptation plans to become a further sectoral tool. In detail, starting from a brief description of the main EU initiatives addressed to enhance cities' adaptation, the paper explores the main features and obstacles of adaptation processes and highlights strengths and weaknesses of current adaptation plans, focusing on their relationships with disaster risk mitigation policies, environmental management and land use planning tools. 


\section{The European path towards cities' adaptation}

Europe, which has been one of the world leaders in the global mitigation policies, only recently has focused on adaptation. As remarked by the EU Strategy on adaptation to climate change, although three quarters of the population of Europe live in urban areas, European cities "are often ill-equipped for adaptation" [2]. Mitigation and adaptation strategies, although complementary, largely differ in their objectives as well as in the temporal and spatial scales of references. Mitigation strategies, which aim at reducing GHG emissions, generally result from international agreements, provide global benefits - although implemented at national or local levels - and refer to a long-term perspective. Adaptation strategies, which aim at adjusting natural or human systems in response to actual or expected climatic stimuli or their effects [11], are strongly characterized as site-specific measures. Moreover, they generally refer to the scale of the impacted system; thus, they are defined and implemented at local level - although sometimes based on wider common platforms at national or upper level - and provide local benefits $[9,12,13]$. Numerous initiatives addressed to improve knowledge and awareness in respect to adaptation issues have been undertaken in Europe starting from the 2007. These initiatives show the growing attention to climate adaptation and, mainly, the growing awareness of the need to enhance cities' resilience in face of climate related risks. Nevertheless, only in the 2013, the EU has issued the Strategy on adaptation to climate change, addressed to enhance preparedness and capacity to respond to the impacts of climate change at different levels, from the European one up to the local level [2]. The strategy promotes the coordination and the sharing of information among the Member States, also through a further development of the European climate adaptation platform (Climate-ADAPT). It encourages the State Members to endorse adaptation strategies, providing funds for national adaptation; supports adaptation in cities, by launching a voluntary commitment based on the Covenant of Mayors initiative; guarantees that adaptation issues will be considered in different sectors of EU policies. The Strategy is a key step towards the adoption and the implementation of effective adaptation strategies at different levels, since in Europe, "adaptation is in most cases still at an early stage, with relatively few concrete measures on the ground. Some Member States have developed sectorspecific plans, such as plans to cope with heat waves and droughts, but only a third carried out a comprehensive vulnerability assessment to underpin policy" [2]. At present, more than half of the European Member States have adopted an adaptation strategy, in many cases followed by action plans. On the contrary, shifting to the city level and even though cities are largely considered as pivotal both to mitigation and adaptation issues, very few European cities have drawn up an adaptation plan. A recent study highlights that, on a sample of 200 large and medium sized cities located in 11 European countries, the " $35 \%$ of the European cities studied have no dedicated mitigation plan and the $72 \%$ have no adaptation plan" [14]. A step forward could be probably done thanks to the recent initiative launched by the European Union. In the wake of what has already been done for promoting the adoption of mitigation plans at city level, in March 2014 the 
Covenant of Mayors Initiative on Climate Change Adaptation has been set up by the European Commission for enhancing cities' involvement in climate adaptation. The EU has devoted the $20 \%$ of the EU budget for 2014-2020 to climate action, including a dedicated 860 Million Euros of climate action funding through the LIFE instrument.

\section{The adaptation process: phases, features and obstacles}

According to numerous scholars and institutional documents, adaptation has to be conceived not as a one-time effort but as a process articulated at least in three interrelated phases [15-17]: a knowledge phase, addressed to assess climate impacts and risks at urban scale; a preparation phase, addressed to define strategies and measures for adaptation; a response and revision phase, addressed to implement, monitor and update the defined measures. As largely emphasized in current literature $[9,18,19]$, in each phase gaps and obstacles to an effective climate change adaptation at city level arise.

In the knowledge phase, the main gaps are related both to the downscaling of climate change models to urban scale and to the assessment of urban vulnerability to climate-related phenomena. Scientific information about the future climate conditions is generally characterized by high uncertainty. Uncertainty, which already permeates the large-scale climate models, is generally exacerbated when climate models are downscaled at city scale. On the city level, climate model projections should pay larger attention to the peculiarities of the urban context that have received little attention up to now [20], and the impact assessment should take into account both the gradual/long term climate-related impacts (increases in the mean temperature or sea level rise) and the sudden shocks due to the changes in the intensity and frequency of extreme events [19, 21, 22]. Significant obstacles in this phase arise from the assessment of urban vulnerabilities to the heterogeneous impacts of climate change. The assessment of the multidimensional concept of vulnerability shows difficulties and uncertainties, largely debated in the field of natural hazards and related, for example, to the need for taking into account the different facets of vulnerability (physical, systemic, economic, etc.) as well as the adaptive capacities of an urban context [11, 23, 24]. Due to the persisting lack of communication among scholars belonging to different scientific communities, the significant results achieved in the field of natural hazards are scarcely mirrored in current adaptation planning. Furthermore, the different temporal perspectives of climate change impacts, combined with the uncertainties that affect long-term urban development trajectories, make even more difficult the assessment of urban vulnerability to the climate-related phenomena.

The uncertainties that characterize the knowledge phase have also repercussions on the preparation phase, addressed to single out effective adaptation strategies and measures. Due to the growing awareness that no "plug and play solutions" are available in face of the heterogeneous impacts of climate change, adaptation measures have to be defined according to the peculiarities of 
local impacts and to the vulnerabilities arising from the physical, functional and socio-economic features of the considered city urban. Hence, the availability of a reliable risk assessment is crucial for identifying priorities, while the availability of in-depth and disaggregate information on the heterogeneous risk factors (hazards, exposure, vulnerabilities) is essential to outline appropriate and spatially distributed adaptation strategies and measures. Adaptation strategies are generally grouped into three main groups [25]: "grey" measures, which rely on technology and civil engineering projects; although sometimes essential, these measures are often inadequate for dealing with more and more common extreme events, are very costly and may generate a false sense of safety; "green" or nature-based measures, currently strongly promoted at EU level, may offer multiple benefits to urban areas (protection against floods, biodiversity, clean air, and so on); they are useful for promoting "multi-objective strategies", crucial in the face of economic crisis as well as of the significant uncertainties of climate trends; "soft" measures, addressed to alter human behaviour, may be very useful for improving response capabilities of local communities and, in so doing, for enhancing urban resilience. Although largely referred to these groups, adaptation measures have to be tailored on each urban context, based on the in-depth analysis of hazard factors and of the related vulnerabilities. Moreover, climate change may affect different sectors (from land use to transportation, from water supply to energy). Hence, the need for coordination across different sectors and for broad partnerships including local communities, non-profit organizations, academic institutions and the private sector has been largely emphasized as a potential barrier to an effective adaptation. Numerous scholars have pointed out, in fact, the importance and, meanwhile, the difficulty in coordinating policies and measures across different levels of government, as well as in involving institutions, private stakeholders and communities [9, 19], also due in many cases to the lack of shared aims for a climate-proof urban development. Finally, the difficulty of integrating adaptation strategies, disaster risk reduction (DRR) policies and land use and transportation planning choices at local level has to be remarked. Hallegatte et al. [25] largely emphasize, for example, that current "land use decisions and zoning may exacerbate or limit the vulnerability of urban dwellers and of infrastructures to the growing threat of climate change". As emphasized by the Rio+20 Declaration too, the integration among disaster risk reduction, resilience and climate risks in urban planning could be a great opportunity for cities and communities - generally dealing with significant resource constraints - to access financial resources and to reduce potential conflicts between climate change issues and other local priorities. According to the Guidelines for Climate Change Adaptation in Cities provided by the World Bank, "cities that are able to integrate adaptation with a broad spectrum of existing planning processes and goals - including priorities in disaster risk reduction, sustainable development, and poverty reduction - will be best positioned to thrive in this new era of climate change" [16].

The complexity and long-term horizon of climate change phenomena, of the evolution of cities as well as of the adaptation processes assign a key role to the revision phase, important for ensuring the effectiveness of the whole process. The implementation of the adaptation measures have to be constantly monitored, 
evaluated and revised, according both to the updating of the available knowledge on climate change and climate-related phenomena and to the effectiveness of policies, programs and measures. Nevertheless, "monitoring and evaluation is proving to be particularly difficult, as indicators and monitoring methodologies have hardly been developed" [2]. Moreover, while the mitigation plans, referring to international or European thresholds, may constrain their strategies to precise targets - which facilitate the control on the effectiveness of the implemented strategies and actions - the adaptation plans often include site-specific measures, referred to the peculiarities of the hit systems. Hence, the monitoring of the adaptation process should also be site-specific. Hence, the revision phase has an inherent complexity and is considered one of the weakest areas of adaptation process, due to the difficulties of monitoring heterogeneous measures, affecting different sectors, acting on different scales and over different time spans. Moreover, the common lack of financial, human and technical resources, of baseline data and historical trends as well as the insufficient sharing of information across different sectors have to be considered.

\section{Adaption plans: strengths and weaknesses}

Strengths and weaknesses of current adaptation plans will be outlined referring to three adaptation plans: the London Mayor's Climate Change Adaption Strategy "Managing Risks and Increasing Resilience, (2011); the Copenhagen Climate Adaptation Plan (2011); the Rotterdam Climate Adaption Strategy (2013). These Plans are at the cutting edge in the European context, since they have been carried out in three climate leader cities, very active both on mitigation and adaptation issues, and closely related to adaptation strategies established on a national level. Referring to recent studies for a detailed description of the features and contents of each plan [27], here we will focus on the potential of these plans for overcoming gaps and obstacles discussed in the previous paragraph, outlining their strengths and weaknesses in respect to the different phases of the adaptation process (fig. 1).

A significant strength of the three plans can be recognized in the common awareness that the numerous challenges that cities have to deal with cannot be faced piecemeal since, in order to achieve sustainability goals, an integrated systems' view of the world is required. Hence, the proposed examples are addressed not only to prevent or reduce the impacts of the numerous climaterelated hazards but also to preserve and enhance the quality of life and prosperity for current and future generations as well as to protect and improve the quality of urban environment. Moreover, all of them are framed into a multilevel and integrated climate policy, developed according to a clear structure of competences and duties both at national and at local level. In the UK, responsibilities for climate change mitigation, adaptation, and energy strategies have been transferred from central government to the Greater London Authority, which is also responsible for producing London-wide strategies for spatial planning and environment. Both Denmark and The Netherlands are characterized by a close cooperation among 
national and local government, showing a long tradition of cooperation among different government bodies, stakeholder organizations and citizens. On the local scale, the three case studies have developed an integrated climate policy, since mitigation and adaptation plans have been issued together or within few years. Such a circumstance is important for guaranteeing synergies and reducing conflicts, which often arise between mitigation and adaptation policies as well as among measures addressed to deal with different hazard factors.

As for the knowledge phase, the case studies present relevant strengths in respect to the assessment of the climate-related hazards. Despite the difficulties related to the downscaling of large-scale climate models, the three plans provide in-depth qualitative and quantitative analyses of the climate-related phenomena on urban scale, based on large-scale scenarios and in-depth studies at local scale.

On the opposite, they show significant weaknesses in respect to the vulnerability and risk assessment. Firstly, none of them provide a clear definition of vulnerability or include a reference to the long and rich tradition of studies and researches on vulnerability carried out in the field of natural hazards. In this field, although methodologies for analysing and assessing vulnerability are still heterogeneous, the concept has been widely recognized as a multi-dimensional one, comprising different aspects (physical, systemic, social, economic, environmental, institutional, etc.), constantly interacting in time and space $[11,23,24,28]$. Moreover, the three plans provide aggregate risk evaluations, generally expressed in monetary terms, paying scarce attention to the different aspects of urban vulnerability and including little or no vulnerability maps (generally only maps of the exposed elements to the different hazard factors are available). This represents a significant weakness of current adaptation plans. In fact, although an aggregate risk assessment is important to identify priority areas and sectors, disaggregate information related to vulnerability features of exposed elements and systems are crucial to outline appropriate adaptation policies. Finally, it is worth noting that, although some of the case studies explicitly refer to resilience, the latter is not defined and no indicators for assessing urban resilience are provided.

As for the preparation/response phase, all the selected plans ground on the awareness that adaptation does not represent a steady state. Hence, they outline dynamic and flexible adaptation processes in face of the numerous uncertainties due to the changing climate projections, to the urban development trajectories as well as to future technical development. Thus, these processes are capable of continuously incorporating new knowledge and revising, accordingly, their goals, objectives and actions. According to this premise, adaptation measures generally refer to a short-term time horizon, even though most of the selected plans provide a detailed economic and temporal program, articulated in respect to different geographical scales or to different urban areas, singling out subjects and tools for the implementation of the foreseen measures.

Another relevant strength of the selected plans is that all of them devote large attention to the "green measures", emphasizing the key role of nature-based solutions for improving green infrastructures in urban areas. The strengthening of green infrastructures is clearly recognized as a multi-objective strategy, capable 
of dealing with the climate change impacts and improving biodiversity in urban areas - providing important services (e.g. clean air) as well as important areas for leisure activities - in one, capable of guaranteeing a better quality of life for citizens.

In respect to the obstacles that generally characterize the preparation phase related to the heterogeneity of policies, to the need for integrating adaptation policies into existing planning tools and, consequently, for coordinating different stakeholders - it is worth noting that all the plans emphasize that climate change adaptation does not require new policies or new planning tools. On the opposite, all of them clearly state that adaptation requires a clear understanding of how climate change may affect the context at stake and the integration of such understanding into all decision-making processes affecting urban development. Furthermore, they emphasize the need for linking adaptation strategies to other policies and projects, as well as to the existing management and maintenance programs and, above all, for mainstreaming adaptation policies into existing disaster risk management and land-use planning process. Among the weaknesses of the analysed adaptation plans, the limited use of "smart" tools capable of improving the awareness of climate-related impacts among different stakeholders has to be underlined. Only the Rotterdam Plan provides smart solutions (e.g. sensor technologies, decision support systems, interactive knowledge tools, etc.) for collecting and disseminating knowledge as well as for building up consensus on adaptation measures and sustaining bottom-up initiatives. A wider use of ICTs could, on the opposite, improve the learning capacities of local stakeholders, which is crucial both for an effective adaptation and for enhancing urban resilience [29].

Finally, in respect to the revision phase all the selected plans - even though they are at cutting edge in Europe - show important weaknesses. Although all the selected plans provide a detailed economic and temporal planning of the proposed measures, in fact, none of them outlines sets of indicators capable of monitoring the effectiveness of the foreseen actions.

\section{Conclusion}

In face of the heterogeneous impacts of the climate-related phenomena (floods, heat waves, droughts, etc.) that numerous European countries are already suffering and following the initiatives started by the EU for improving knowledge and awareness in respect to adaptation issues, numerous European cities have started an adaptation process, despite the significant obstacles due to the uncertainties in the future climate scenarios. This contribution, grounding on current literature and on the comparative analysis of some recent adaptation plans at urban scale, focuses on gaps and obstacles arising from current adaptation processes and on the main strengths and weaknesses of current adaptation plans. In detail, the in-depth analysis of current literature on cities' adaptation to climate change and of three recent adaptation plans has allowed us to better understand challenges and opportunities arising from the on-going adaptation processes. On the one hand, in fact, they shed light on the numerous difficulties related to the different phases of the process. On the other hand, they clearly underline that adaptation planning 
might be a great opportunity for promoting a sustainable growth, enhancing urban resilience in face of "the unavoidable climate impacts and their economic, environmental and social costs" [2].

Table 1: Strengths and weaknesses of the London, Copenhagen and Rotterdam adaptation plans (strengths in blue; weaknesses in green).

\begin{tabular}{|c|c|c|c|c|}
\hline \multirow{2}{*}{\multicolumn{2}{|c|}{ Key aspects }} & \multicolumn{3}{|c|}{ Adaptation Plans } \\
\hline & & London (2011) & Copenhagen (2011) & Rotterdam (2011) \\
\hline \multirow{3}{*}{$\begin{array}{c}\text { Integrated and Multilevel } \\
\text { Climate Policiy }\end{array}$} & Avallablity of a National Climate & $\checkmark$ & $v$ & $\checkmark$ \\
\hline & $\begin{array}{l}\text { Stratergy } \\
\text { Availibility of a Mitigation Strategy }\end{array}$ & $\checkmark$ & $\checkmark$ & $v$ \\
\hline & $\begin{array}{l}\text { Integration between Mitigation and } \\
\text { Adaptation Strategy }\end{array}$ & $\checkmark$ & $v$ & $\checkmark$ \\
\hline Adaptation Process & $\begin{array}{l}\text { Design of an Adaptation Process Capable } \\
\text { of Dealing with Uncertainties }\end{array}$ & $v$ & $v$ & $\checkmark$ \\
\hline \multirow{7}{*}{ Knowledge Phase } & $\begin{array}{l}\text { Hazard Assessment: availability of in- } \\
\text { depth climate studies at local scale }\end{array}$ & $\checkmark$ & $v$ & $\checkmark$ \\
\hline & $\begin{array}{l}\text { Definition of vulnerability as } \\
\text { multidimensional concept }\end{array}$ & & & \\
\hline & $\begin{array}{l}\text { Availability of vulnerability maps (in the } \\
\text { on-line documents) }\end{array}$ & Exposure Maps & & $\sqrt{2}$ \\
\hline & Definition of resilience & & & \\
\hline & Risk Assessment & $\begin{array}{c}\text { Combination of hazard } \\
\text { probability and damage cost }\end{array}$ & $\begin{array}{l}\text { Damage cost for different } \\
\text { hazard scenarios }\end{array}$ & $\begin{array}{l}\text { Combination of hazard and } \\
\text { vulnerability }\end{array}$ \\
\hline & Multi-Risk Assessment & & Qualitative Assessment & \\
\hline & Typology of Available Scenarios & Hazard & Hazard & Risk \\
\hline \multirow{10}{*}{$\begin{array}{c}\text { Preparation/Response } \\
\text { Phase }\end{array}$} & $\begin{array}{l}\text { Short Term Horizon for the Adaptation } \\
\text { Measures }\end{array}$ & $v$ & 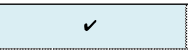 & 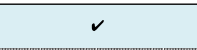 \\
\hline & $\begin{array}{l}\text { Detailed Economic and Temporal } \\
\text { Planning of Adaptation Measures }\end{array}$ & v & $\boldsymbol{v}$ & \\
\hline & $\begin{array}{l}\text { Measures Articulated for Geographical } \\
\text { Scales and/or Typology of Urban Areas }\end{array}$ & & $v$ & 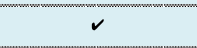 \\
\hline & Multi-Objective Nature-Based Solutions & $\checkmark$ & $\checkmark$ & $\checkmark$ \\
\hline & $\begin{array}{l}\text { Integration of Large Scale and Small } \\
\text { Scale Solutions }\end{array}$ & 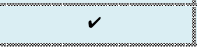 & $\sqrt{2}$ & 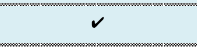 \\
\hline & Availability of Guide-Projects & & $v$ & $v$ \\
\hline & $\begin{array}{l}\text { Availability of Smart Tools for } \\
\text { Knowledge Dissemmination among } \\
\text { different Stakeholders }\end{array}$ & & & v \\
\hline & \begin{tabular}{|l} 
Availability of Smart Tools for \\
Improving Awareness of People and \\
Institutions
\end{tabular} & & & v \\
\hline & \begin{tabular}{|l} 
Integration of Climate Change \\
Adaptation (CCA) with Disaster Risk \\
Reduction (DRR)
\end{tabular} & $v$ & $v$ & 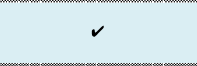 \\
\hline & $\begin{array}{l}\text { Integration of CCA and DRR into Urban } \\
\text { Planning Tools }\end{array}$ & $v$ & $v$ & $\checkmark$ \\
\hline Revision Phase & \begin{tabular}{|l} 
Availability of Indicators for the \\
Monitoring of the Adaptation Process
\end{tabular} & & & \\
\hline
\end{tabular}

In respect to the opportunities, it is worth emphasizing that, in line with the Rio+20 Declaration "The Future we want" [3], disaster risk reduction as well as climate adaptation policies are crucial for promoting a sustainable urban development. Furthermore, it has to be underlined that climate change and, namely, its increasing impacts on urban areas are forcing planners to pay a renewed attention to the principles of environmental planning. Environmental planners have largely investigated the concept of adaptation of ecological and socio-ecological systems to external threats since the Seventies [30-32]. Such issue has been currently revisited and improved by the numerous scholars who have contributed to the debate on sustainability and resilience [29, 33, 34]. In respect to the challenges, it is worth underlining that the selected experiences do not seem to fully benefit by the significant results already achieved in the field of 
risk analysis. Despite the numerous projects funded by the European community in order to promote the building up of a shared knowledge and common methodologies among the scholars working in the field of natural hazards and those involved in studies and research on climate change, a difficulty in transferring concepts, methods and results from one field to the other still persists. Such difficulty is even more troubling in the light of the close relationships between climate related impacts and the increasing occurrence of natural hazards (e.g. floods) that largely emphasize the need for better integrating climate change adaptation (CCA) and disaster risk reduction (DRR) into the wider framework of urban planning processes. To this aim, contents and roles of urban planning should be largely reviewed. Urban planning processes - which have largely contributed to the occurrence of more frequent, severe and unpredictable climate-related disasters in urban areas - are currently called to play a pivotal role both as a technical mean by which climate policies and disaster risks can be effectively delivered [39] and as the arena in which all competing goals and land uses have to be negotiated and reconciled [10].

\section{References}

[1] Klein, R.J.T., Schipper E. L. Dessai S. (2003), Integrating mitigation and adaptation into climate and development policy: three research questions, Tyndall Centre for Climate Change Research, Working Paper 40, http:// www. tyndall.ac.uk/sites/default/files/wp40.pdf.

[2] EC (2013), An EU Strategy on adaptation to climate change, COM (2013) 216 final, Brussels, 16.4.2013 http://eurlex.europa.eu/LexUriServ/LexUri Serv.do? uri=COM:2013:0216:FIN:EN: PDF.

UN (2012) The Future We Want, http://www.un.org/disabilities/ documents/rio20_outcome_document_complete.pdf.

[3] Birkmann J., Garschagen M., Kraas F., Quang N. (2010), “Adaptive urban governance: new challenges for the second generation of urban adaptation strategies to climate change", Sustainable Science 5(2): 185-206.

[4] EU (2011), Climate Friendly Cities. A Handbook on the Tasks and Possibilities of European Cities in Relation to Climate Change. http://politicadecidades.dgotdu.pt/news/Documents/Climatefriendly_cities_2011[1].pdf.

[5] IPCC (2013), Climate change 2013: The physical science basis. http://www.climatechange2013.org/images/report/WG1AR5_ALL_FINA L.pdf.

[6] Solomon, S., Qin, D., Manning, M., Chen, Z., Marquis, M., Averyt, K.B., Tignor, M., Miller, H.L. (2007), Contribution of Working Group I to the Fourth Assessment Report of the Intergovernmental Panel on Climate Change, Cambridge University Press, Cambridge, UK.

[7] ICLEI (2011), Financing the Resilient City. A Demand Driven Approach to Development, Disaster Risk Reduction and Climate Adaptation - An ICLEI White Paper. International Council for Local Environmental Initiatives (ICLEI), Bonn. 
[8] Bulkeley, H, Schroeder, H., Janda, K., Zhao, J., Armstrong, A., Yi Chu, S. and Ghosh, S. (2009), Cities and Climate Change: The role of institutions, governance and urban planning. Report prepared for the World Bank Urban Symposium on Climate Change, Durham, Oxford. http://www.eci. ox.ac.uk/publications/downloads/bulkeley-schroeder-janda09.pdf.

[9] Estrella, M., Renaud F.G. and Sudmeier-Rieux K. (2013), Opportunities, challenges and future perspectives for ecosystem-based disaster risk reduction. In Renaud F.G., Sudmeier-Rieux K. and Estrella, M., The Role of Ecosystems in disaster risk reduction, United Nations University Press.

[10] UNISDR (2009), UNISDR Terminology on Disaster Risk Reduction, http://www.unisdr.org/ eng/terminology/terminology-2009-eng.html.

[11] Walsh C.L., Dawson, R.J., Hall J.W., Barr S.L., Batty M., Bristow A.L., Carney S., Dagoumas A.S., Ford A.C., Harpham C., Tight M., Watters H., Zanni A.M. (2011), "Assessment of Climate Change Mitigation and Adaptation in Cities", Urban Design and Planning, Vol. 164, Issue DP2.

[12] EEA (2012), "Urban Adaptation to Climate Change in Europe, Challenges and opportunities for cities together with supportive national and European policies", EEA Report n 2, Copenhagen.

[13] Reckien D., Flacke J., Dawson R. J. et al. (2013), Climate change response in Europe: what's the reality? Analysis of adaptation and mitigation plans from 200 urban areas in 11 countries, DOI 10.1007/s10584-013-0989-8, Springer Science+Business Media Dordrecht.

[14] Hennessy, K., Fitzharris, B. et al. (2007), Australia and New Zealand. Climate Change 2007: Impacts, Adaptation and Vulnerability, Cambridge University Press, Cambridge, UK, 507-540. http://www.ipcc.ch/publications_and_data/ar4/wg2/ en/ch11.html.

[15] The World Bank Group (2011), Guide to Climate Change Adaptation in Cities, http://siteresources.worldbank.org/ INTURBANDEVELOPMENT/ Resources/336387-1318995974398/GuideClimChangeAdaptCities.pdf.

[16] UN, Adaptation Committee (2013), The State of Adaptation under the United Nations Framework Convention on Climate Change 2013 Thematic Report. http://unfccc.int/files/adaptation/cancun_adaptation_framework/ adaptation_committee/ application/pdf/ac_2013_report_high_res.pdf.

[17] Adger, W. N., Lorenzoni I., O’Brien K. L., eds., (2009), Adapting to Climate Change: Thresholds, Values, Governance. Cambridge University Press.

[18] Corfee-Morlot, J., Cochran I., Hallegatte, S., Teasdale P. J. (2011) Multilevel risk governance and urban adaptation policy, Climatic Change (2011) 104:169-197 DOI 10.1007/s10584-010-9980-9.

[19] IPCC (2007), "Climate change 2007: Synthesis Report", Geneva, Switzerland. http://www.ipcc. ch/ipccreports/ar4-syr.htm.

[20] Wilbanks T.J., Romero Lankao P., Bao M., et al. (2007), Industry, settlement and society. Climate change 2007: impacts, adaptation and vulnerability. In: Parry M.L., Canziani O.F., Palutikof J.P., van der Linden P.J., Hanson C.E., eds., Contribution of Working Group II to the Fourth 
Assessment Report of the Intergovernmental Panel on Climate Change. Cambridge University Press, Cambridge, pp. 357-390.

[21] Hunt A., Watkiss, P. (2011), Climate change impacts and adaptation in cities: a review of the literature, Climatic Change (2011) 104: 13-49 DOI 10.1007/s10584-010-9975-6.

[22] Birkmann, J., ed., (2006), Measuring vulnerability to natural hazards. Towards disaster resilient societies. United Nation, University Press.

[23] Menoni, S., Costa, L., Galderisi A., and Margottini C. (2011), Deliverable 4.1- Methodological framework for an Integrated multi-scale vulnerability and resilience assessment, Ensure Project, http:/www.ensureproject.eu/ ENSURE_Del4.1.pdf.

[24] EEA (2013) Adaptation in Europe. Addressing risks and opportunities from climate change in the context of socio-economic developments, EEA Report $\mathrm{n}^{\circ}$ 3, http://www.eea.europa.eu/ publications/ adaptation-in-europe.

[25] Hallegatte, S., Henriet, F., Corfee-Morlot, J. (2011), The economics of climate change impacts and policy benefits at city scale: a conceptual framework, Climatic Change (2011) 104:51-87 DOI 10.1007/s10584-0109976-5.

[26] Galderisi, A., (2014), Climate Change Adaptation. Challenges and Opportunities for Smart Urban Growth, TeMA 1 (2014) 43-67 DOI: 10.6092/1970-9870/2265.

[27] Galderisi A., Bonadonna C., Delmonaco G., Ferrara F.F., Menoni S., Ceudech A., Biass S., Frischknecht C., Manzella I., Minucci G., Gregg C. (2013) Vulnerability Assessment and Risk Mitigation: The Case of Volcano Island, Italy, Landslide Science and Practice, Volume 7: Social and Economic Impact and Policies, Springer Berlin Heidelberg, 55-64, DOI: 10.1007/978-3-642-31313-4 8.

[28] Davoudi S., Brooks E., Mehmood A., (2013) Evolutionary Resilience and Strategies for Climate Adaptation, Planning Practice \& Research, 28:3, 307-322, http://dx.doi.org/ 10.1080/02697459.2013.787695.

[29] Whiston Spirn, A. (1973), Woodlands New Community, Guidelines for site Planning, http://www.annewhistonspirn.com/pdf/Spirn-Woodlands-1973.pdf.

[30] Lynch. K. (1990), Wasting Away. Sierra Club Books.

[31] Steiner, R.F. (2006), The Essential Ian McHarg, Writings on Design and Nature, Island Press.

[32] Folke C., Carpenter S.R., Walker B., Scheffer M., Chapin T., Rockstrom J. (2010) "Resilience Thinking: integrating Resilience, Adaptability and Transformability", Ecology and Society, 15(4):20. http://www.ecologyand society.org/vol15/iss4/art20/.

[33] Galderisi, A. (2014), Urban Resilience: a framework for empowering cities in face of heterogeneous risk factors, A|Z Journal - Cities at risk - Vol. 11 Issue 2 (forthcoming).

[34] Davoudi, S., Crawford, J., Memhood, A. (2009), Planning for Climate Change: Strategies for Mitigation and Adaptation for Spatial Planners, Earthscan. 